\title{
Legal, ilegal, legítimo. Usuarios de pasta base de cocaína en Montevideo
}

Legal, illegal, legitimate. Cocaine paste users in Montevideo

\section{Giancarlo Albano}

Antropólogo. Facultad de Humanidades y Ciencias de la Educación (UdelaR). Montevideo, Uruguay. giancaat@gmail.com

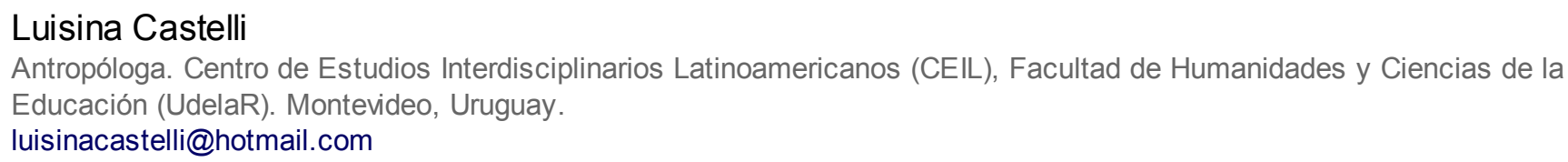

\section{Emmanuel Martínez}

Antropólogo. Facultad de Humanidades y Ciencias de la Educación(UdelaR). Montevideo, Uruguay. ejm79ejm@hotmail.com

\section{Marcelo Rossal}

Antropólogo. Departamento de Antropología Social, Facultad de Humanidades y Ciencias de la Educación (UdelaR). Montevideo, Uruguay.

mrossal@yahoo.com

\section{RESUMEN}

Este trabajo estudia las relaciones entre lo legal e ilegal y las significaciones de lo legítimo en el contexto de una aproximación etnográfica con usuarios de cocaínas fumables en Montevideo (Uruguay). El objetivo es explorar las configuraciones que adquieren estas categorías, y las formas en que inciden en las trayectorias de vida, modos de provisión y dinámicas cotidianas de los usuarios de pasta base de cocaína (PBC), población sobre la cual se proyectan tanto los discursos estigmatizantes como los aspectos más cotidianos de la violencia estatal. En consecuencia, su posición social desacreditada por el estigma de ser usuarios de PBC produce prácticas y significados que se manifiestan en el espacio público, que se tensionan con la normativa vigente y que, en buena parte de los casos, acaban bajo la órbita del sistema penal.

\section{ABSTRACT}

This paper studies the relationships between the conceptions legal and illegal as well as the meanings of the legitimate in the context of an ethnographic approach involving over 300 cocaine paste users (PBC) in Montevideo (Uruguay). The aim of this article is to explore the configurations that these categories acquire, and the ways in which they influence the paths of life, modes of provision, and daily dynamics of the subjects, under the interpretation that these individuals represent the population onto which both stigmatizing discourse and the most mundane aspects of state violence are projected. Consequently, the social position of these subjects is discredited by the stigma of being cocaine paste users, and leads to practices and meanings that are manifested in the public space, going against current laws and in many cases ending up in the penal system.

PALABRAS CLAVE

pasta base de cocaína | moralidades | legal/ilegal

KEYWORDS

cocaine paste | moralities | legal/illegal

\section{Introducción}

El presente artículo se enfoca en las concepciones sobre lo legal y lo ilegal y las significaciones de lo legítimo entre usuarios de pasta base de cocaína (PBC) de la ciudad de Montevideo (Uruguay) (1). Este es producto del proyecto "Efectos y prácticas de consumo problemático de cocaínas fumables en poblaciones ocultas" (Albano y otros 2014); el estudio, de tipo etnográfico, se desarrolló en conjunto con una encuesta basada en la metodología RDS (Respondant-Driven Sampling - muestreo guiado por el encuestado) que tenía por objetivo conocer datos sobre una población "oculta" (Feldman y Aldrich 1990) con consumo problemático de PBC en un barrio de Montevideo (2). 
Acompañando este proceso, nuestro trabajo implicó la realización de entrevistas, observación in situ y diálogo cotidiano con los hombres y mujeres que participaron en la investigación. Se realizaron cuarenta entrevistas ahondando en las trayectorias de vida de estos sujetos y un registro sistemático de las charlas informales con los más de trescientos participantes que tuvo la encuesta. El equipo realizó asimismo una serie de recorridos por la zona, observando lugares de referencia, achiques (3) y demás espacios donde muchos de ellos viven diariamente.

Los requisitos para participar del estudio cuantitativo, y por ende del trabajo etnográfico, eran tener entre 18 y 64 años y un consumo sostenido de PBC (con una frecuencia de por lo menos una vez a la semana) en los últimos 6 meses. Las y los participantes provenían de distintos barrios, principalmente de la zona Oeste de la ciudad, por proximidad al barrio en donde se había instalado el dispositivo para realizar la encuesta. Concurrían al local por invitación de otro/a que había participado antes; cada uno podía invitar hasta tres conocidos y recibía un incentivo por ello.

El trabajo etnográfico permitió aproximarnos a la complejidad de las relaciones entre las categorías legal e ilegal, las moralidades y las percepciones y prácticas de estos sujetos, mayoritariamente pertenecientes a los sectores más pobres de la sociedad uruguaya, es decir, con una mayor vulnerabilidad social y sobre quienes recaen comúnmente la vigilancia continua y la violencia estatal (Fraiman y Rossal 2011).

En este artículo se problematizarán las construcciones (normativas y sentido atribuido) en torno a las categorías mencionadas, poniéndolas en relación a: 1) el espacio público y el espacio privado; 2) las moralidades de provisión y de cuidado; y 3 ) las trayectorias de vida de estos sujetos, particularmente en los casos que han tenido pasajes por centros de reclusión (sean para mayores de edad o adolescentes).

\section{Legal/ilegal y la construcción de la legitimidad}

Hay varios motivos que hacen pertinente atender las tramas entre lo legal/ilegal y las construcciones de la legitimidad en esta población. Entre ellos, el hecho de que si bien en Uruguay consumir drogas es una actividad lícita, consumir PBC es claramente ilegítimo, y el suministro y venta de la sustancia es ilegal, por tanto para consumirla hay que participar de un mercado ilegal, inevitable generador de violencia interpersonal (Silva de Sousa 2004).

En Uruguay, de acuerdo a la legislación vigente, el consumo de estupefacientes no se encuentra penado, aunque sí lo está su comercialización. La ley n 17.016 establece en su artículo 31 que "quedará exento de pena el que tuviera en su poder una cantidad razonable destinada exclusivamente a su consumo personal, con arreglo a la convicción moral que se forme el Juez a su respecto, debiendo fundamentar en su fallo a las razones que la han formado".

Punto éste que genera contradicciones, por ejemplo en lo que refiere al desigual tratamiento jurídico que reciben situaciones similares, que quedan libradas a "la convicción moral de los juzgadores" y constituye muchas veces "una forma encubierta de penalizar la posesión de drogas para consumo personal" (Bardazano 2012: 58).

Asimismo, Garibotto (2010) muestra que mientras que entre un tercio y la mitad de las incautaciones realizadas de las diferentes sustancias son de menos de 10 gramos, las penas mínimas excarcelables no parecen reflejarse en los procesamientos, ya que los procesados sin prisión son muy pocos:

"[La PBC] merece una reflexión especial, ya que si bien existen directivas específicas para atacar especialmente los puntos de venta de esta sustancia, se puede observar que en 258 casos [aproximadamente un $25 \%$ del total] se incautaron 2 gramos o menos de PBC. Esto plantea el interrogante de si, efectivamente, se está deteniendo a los traficantes de dicha sustancia o están siendo detenidos los usuarios más vulnerables" (Garibotto 2010: 86).

Como se ve, el eje legal/ilegal es bastante más problemático de lo que podría suponerse a priori. Considerando las disposiciones normativas, y las relaciones que se generan en el espacio social (en estrecha conexión con la estigmatización que recae sobre los usuarios problemáticos de PBC), es posible plantear que estos pasajes grises de la legalidad -que los sujetos con los que nos encontramos conocen y 
sufren en su cotidiano- se conectan de formas complejas con las prácticas consideradas legítimas e ilegítimas. La trama social se define desde las estructuras estatales, pero también desde las producciones de sentido que se dan entre los sujetos.

Desde discursos socialmente validados, como el periodístico y el policial, se entiende que los usuarios de PBC desarrollan prácticas ilegales -y por consiguiente ilegítimas, desde su mirada- para proveerse del consumo; ello puede corresponderse con hechos de la realidad, pero no en todos los casos, ni de forma exclusiva.

Pero en el contexto mismo en que se producen, algunas de estas prácticas se sostienen en representaciones diferentes a las hegemónicas y las que establece el orden jurídico, de modo tal que ciertas manifestaciones de lo ilegal pueden adquirir carácter legítimo entre estos sujetos. Ejemplo de actividad ilegal pero legítima para proveerse es el vender artículos que fueron tomados de propiedades privadas "abandonadas" o hurtos en propiedades públicas; ejemplo de concordancia entre lo legal y lo legítimo es la práctica de volquetiar, esto es recolectar de la basura artículos reciclables (plástico, cartón, lata); una práctica ilegal considerada ilegítima es el hurto en sus propias casas, en especial en el hogar materno.

El ordenamiento jurídico y el sistema penal es externo a los sujetos, pesa sobre ellos y se manifiesta en la detención, el confinamiento, la institucionalización; el efecto de lo legal/ilegal ocurre en la relación del sujeto con las estructuras jurídicas del Estado, pero estas normativas pueden o no tener un sentido válido en sus vidas: perder bien o perder mal, en términos de nuestros interlocutores. Para ellos, nunca es grato perder. ser detenido, procesado y encarcelado; pero no es lo mismo perder mal que perder bien.

Perder mal es cuando no "era para estar preso", cuando la persona es embagayada o engarronada (causa penal armada con pruebas falsas puestas por algún policía o grupo de policías contra una persona, en general, con antecedentes penales) o cuando se estima que la situación, aunque configure delito, no es una acción ilegítima, por ejemplo, comprar y distribuir drogas entre amigos. Perder bien, en cambio, implica el reconocimiento del procesado de la causa en la cual se encuentra involucrado, por ejemplo en ocasión de un robo con violencia (delito de "rapiña" para el Código Penal uruguayo).

Así, las valoraciones de lo legítimo y lo ilegítimo se reconfiguran según las moralidades y las condiciones de vida propias del universo de significación en el cual los sujetos se desenvuelven, si bien también se producen en relación al binomio legal/ilegal dado por la legislación vigente.

Aunque el consumo de PBC no es ilegal, su usuario está unánimemente deslegitimado. En un primer momento de interlocución algunos usuarios justifican el consumo bajo la premisa de me gusta la droga, soy drogadicto, siempre está ahí. Pero a medida que se establece cierta confianza, se manifiesta la necesidad de dejar el consumo o disminuirlo, incluso en muchos casos enunciar un reclamo de mayor control del ingreso de la sustancia que los arruina. Así, poder manejarla no sería tan grave como haber perdido todo o estar arruinado. Y aparece una concepción moral clara: el ideal es tener un trabajo, la casa, la familia, en algunos casos también consumir tranqui o ir llevandolá. Esta forma de consumo sería legítima, pero para muchos ello sería imposible, ya que también forma parte del discurso el que si fumás uno, no parás.

\section{Espacio público y espacio privado: cante, calle, barrio y casa}

Consumir PBC implica establecer vínculos que permitan acceder a la sustancia y a los recursos para obtenerla. Cuando se llega a un punto en que el consumo es abusivo (4), comienzan a cambiar las relaciones cotidianas. Este es uno de los momentos donde emergen tensiones explícitas entre lo legal/ilegal, pues en determinados aspectos este marco no se corresponde con las moralidades de los propios usuarios de PBC y sus familias.

Estando en situaciones de consumo problemático, los usuarios suelen pasar buena parte del tiempo procurando (5), es decir, recorriendo distintos lugares buscando el modo de conseguir la droga. En la calle, las prácticas y corporalidades de los usuarios se hacen más visibles y deslegitimadas, mientras que en ámbitos donde el consumo y/o la venta de sustancias ilegales como la PBC es una práctica más común, como en los cantes (6), las formas que adoptan las relaciones de solidaridad y sanción social son otras. En el ámbito de la casa, en cambio, el consumo tiene los límites que marca la familia: muchos usuarios 
declaran que están en la calle porque su uso de PBC se hace incompatible con la vida familiar.

En relación al espacio público, "calle", "barrio" y "cante" son referidos por nuestros interlocutores no de manera indistinta sino poniendo de manifiesto diferentes tipos de apropiación de estos espacios. En la calle el sujeto está expuesto a mayores riesgos, como la sanción policial y la violencia física. Por eso la calle constituye un espacio (7) donde se tensionan las moralidades que definen que ciertas prácticas legales e ilegales sean consideradas o no legítimas por estos sujetos. La calle refiere a cualquier espacio desligado de lo personal y por lo tanto donde se pueden transgredir ciertas normas, pero también donde se corren más riesgos. Las otras dos categorías -barrio y cante- son utilizadas para señalar los lugares de residencia donde el consumo se practica de un modo más privado o resguardado (el barrio) (8), y aquellos donde la precariedad económica y social es el rasgo característico, donde el consumo adquiere mayor cotidianeidad o es más visible para quienes allí viven, sean o no usuarios (el cante).

El cantegril o cante es un barrio asentado sobre un terreno, en general público, de modo informal (el modo políticamente correcto de llamarlo es asentamiento irregular), pero cante y asentamiento son, en Uruguay, epítome del "barrio marginal"; los partes policiales, de hecho, llaman zona marginal a los cantes (9). En estos espacios de la ciudad la propiedad de la tierra es motivo de disputa y las casas que allí se asientan conforman asimismo un mercado informal, pues se pueden comprar o vender, aunque también existen coacciones privadas para realizar tal venta, o incluso hay expulsiones del barrio producto de la violencia que pune el incumplimiento de normativas informales, como por ejemplo la que indica que no debe denunciarse a quienes cometen actividades ilícitas. Al vecino que toca pito, le pueden dar cumbia (Fraiman y Rossal 2009), lo cual es un conjunto de amenazas en forma de apedreamientos nocturnos, por ejemplo, que pueden llegar literalamente a quemar el rancho. También es interesante ver cómo se establecen en el cante relaciones de vecinazgo entre sujetos que no son reconocidos como vecinos por aquellos otros que habitan el barrio formal que lo circunda. Esto tensiona los derechos ciudadanos, pues la vivienda digna está consagrada como derecho constitucional en Uruguay. El Estado podrá realojar a los habitantes de los asentamientos irregulares, pero no le resultará legal expulsarlos, ni tampoco legítimo en el ámbito del espacio público, en tanto que espacio de ejercicio de la ciudadanía, aunque sí pueda haber reclamos del "espacio público local" (Saraví 2004), el barrio, cuyo habitante hegemónico es el vecino, sujeto de las políticas de participación política desde los años 90 en Montevideo (Veneziano 2008, Fraiman y Rossal 2011a). Ahora bien, ¿un asentamiento en medio de un barrio formal constituye un "espacio público local"? ¿Dónde empieza y termina tal espacio? Al no ser el cante reconocido como un actor/lugar legítimo de la "participación local" a menos de que inicie un proceso de formalización, los derechos que les son reconocidos a sus habitantes pasan por los derechos ciudadanos del espacio público, sin adjetivos, en tanto que espacio de la participación política más universal, en el marco del Estado nación (Fraiman y Rossal 2009).

El espacio privado, reservado a la familia, se presenta por lo general como aquel donde el consumo se oculta, es decir donde adquiere la máxima expresión de ilegitimidad en tanto interrumpe el cumplimiento de las responsabilidades morales autoasignadas por el sujeto: proveer a la familia en el caso del varón, cuidar a los hijos en el caso de la mujer (10).

Pero, además, lo personal, vinculado a lo privado, difícilmente encuentre una continuidad en el espacio público, vinculado a lo colectivo. En este sentido, los relatos coinciden en que al reconocer que el uso de PBC está afectando el vínculo con sus familiares, algunos usuarios abandonan el hogar y pasan a vivir en la calle (11). Viviendo en la calle, muchos de ellos se rebuscan volquetiando, lo que supone amplios recorridos por distintos espacios urbanos. Estos recorridos se amplían y tienden a ser fluctuantes en la búsqueda de las bocas (12), y es muchas veces en estos mismos lugares donde se establecen prácticas delictivas, de acuerdo al Código Penal (13), pero admisibles o legítimas entre los usuarios.

Es común también que viviendo en la calle algunos usuarios estén con una pareja afectivo-sexual o con algún compañero (14) con quien comparten la comida, cuidan mutuamente sus pertenencias y pasan el tiempo. En general, aunque conozcan muchos otros usuarios de PBC, o incluso achiquen juntos, sus recorridos son mayoritariamente solitarios y dan cuenta de una práctica de cuidado de la integridad física, por contraposición a lo que sería esperable en el contexto doméstico: estar en familia, juntos. Esto sucede, por un lado, porque generalmente la PBC no se comparte; pero también, porque la calle es un espacio donde se corren riesgos, con lo cual lo más prudente es caminar solo (15). Hay que notar que la calle es un espacio habitual entre aquellos que sufren adicción a la PBC, a diferencia de otros usos abusivos como 
puede ser el de cocaína inhalada.

Es por eso que las prácticas que se realizan en la calle y en el hogar, como los sentidos que les atribuyen (16), se contraponen, y mientras la dependencia al consumo es fuerte no es posible habitar ambos espacios al mismo tiempo, aunque en la trayectoria de los sujetos, la casa, la calle e incluso la cárcel, forman parte de una suerte de continuo recurrente.

La siguiente observación ilustra un recorrido por uno de los barrios donde viven varios de nuestros entrevistados, donde se pueden visualizar las tensiones referidas:

"En el recorrido encontramos la parte abandonada de la fábrica La Aurora. Había varias entradas sin ningún obstáculo y la vereda cubierta de pastizal. El lugar está próximo a la estación de trenes Yatay, lugar sobre el cual varios de nuestros entrevistados comentaron que pernoctaban ellos mismos y otros. Como aún era temprano en la tarde entraba abundante luz en ese lugar inmenso; se encontraba en total abandono pero por algunos objetos que había vimos que efectivamente era utilizado como achique. Había ropa, incluso dos jeans parecían colgados como si estuviesen secándose luego de un lavado, si no fuese porque la mugre en ellos era evidente. También había alguna almohada, latas, restos de fogón y tizne en las paredes, cables y partes que pertenecieron a electrodomésticos, además de distintas escrituras y graffitis por doquier. Minutos más tarde el Manager (17) nos confirmaría que allí duermen algunos pero que "no cualquier negro entra ahí de noche porque impresiona" (18). El lugar para dormir puede mantenerse cierto tiempo, pero va cambiando y hay varios aspectos que hacen que suceda así. En la calle es imposible encontrar un lugar cómodo y siempre se está a la deriva de un lado a otro dependiendo de las circunstancias que se presentan. De eso hablamos brevemente con el Manager, a quien cruzamos a unas pocas cuadras luego de abandonar aquella mole. Dijo que venía de la ferretería, donde vendió unos hierros e iba camino a la farmacia (19). Actualmente estaba pasando la noche en un escampado cerca de uno de los puentes que cruzan el arroyo Miguelete; dice que prefiere un lugar donde no lo molesten, como sí ocurre por ejemplo en la estación de trenes, de donde la policía los corre a diario, y donde incluso hay un cartel que anuncia Prohibido Pernoctar".

Resulta legítimo contar con un lugar para descansar o pasar la noche, pero se trata de una práctica ilegal cuando se está ocupando una propiedad ajena. Sin embargo, ¿alguien dudaría de entrar a una propiedad abandonada a dormir cuando se está viviendo el día a día en la calle? En este sentido, la precariedad aparece como un elemento que tensiona las relaciones entre lo legal/ilegal. Es también en la calle donde ocurren diverso tipo de intercambios, y también aquí los límites entre lo lícito e ilícito se tornan difusos, por los significados que se le atribuyen en relación a contextos concretos, como continúa ilustrando nuestro encuentro con el Manager:

"Al Manager se lo veía bien, estaba prolijo con un jean y una camisa verde, pero él nos desengañó de esa suposición diciendo que lo veíamos así porque había logrado dormir el día anterior, luego de una semana de gira (20) durante la cual sólo descansaba a razón de una o dos horas diarias. Antes de preguntar cómo había conseguido el dinero para solventar esos días de gira, él se anticipó diciendo que hallaron junto a otros muchachos un barco encallado próximo a la Central Batlle (21); de ahí obtuvieron todo tipo de artículos que vendieron en distintos lugares del barrio: 'surtimos de lonas a todos los quiosquitos', comentó entusiasmado y entre risas. Con algunas personas o en determinados lugares estos muchachos ya son conocidos dado que son del barrio, (por ejemplo en esa ferretería donde vendió algunos fierros, o en los almacenes). Así, el intercambio entre los comerciantes y los usuarios de PBC oscila entre la conveniencia mutua y la distancia que impone la estigmatización".

¿A quién se le recriminaría lo ilegal?, ¿al Manager y los demás muchachos por vender objetos de un barco abandonado o a los comerciantes por comprar esos mismos objetos? Hay que entender que es legítimo (e indudablemente necesario), hacerse de los medios para subsistir viviendo en la calle, y en este caso quizá resulte mucho más legítimo obtener el mismo dinero de un barco abandonado que perpetrando otro tipo de actividades ilícitas como puede ser el robo a una persona.

\section{Moralidades de provisión y cuidado}

Ya se mencionó que en la construcción de estas relaciones múltiples juegan un papel preponderante las 
moralidades que interpelan a los hombres, fundamentalmente una moralidad de la provisión, y a las mujeres, una moralidad vinculada al cuidado. Es por ello que para nuestros interlocutores varones puede considerarse razonable abandonar la casa cuando el consumo afecta las relaciones familiares y cuando no puede cumplirse con el imperativo de la provisión; del mismo modo, es legítimo para las mujeres establecer una relación de pareja con otro hombre que efectivamente provea a la familia, cuando quien era "su marido" no está presente en el hogar, aunque aquel continúe idealizando la relación establecida con "su mujer". Varios entrevistados contaron que "su mujer" los espera en la casa, a pesar de estar alejados de su familia por varios meses, incluso por períodos de tiempo más prolongados (22).

Creemos que estas moralidades que implican los valores más tradicionales, se encuentran más vigentes entre nuestros interlocutores que en otros sectores sociales. Pero es fundamental notar como estas se tensionan con las transformaciones estructurales de la economía, la precarización e informalización del trabajo para buena parte de la población, y la incapacidad de cumplir con el mandato de "proveer" para muchos hombres, ya que acceden solo circunstancialmente al mercado laboral formal y dependen en buena medida del trabajo informal e incluso de actividades ilícitas. Estos cambios repercuten en las relaciones entre varones y mujeres, y las violencias de género que se producen. Algo semejante encontraba Bourgois (2010) estudiando el caso neoyorquino en los 80. Entre los habitantes de El Barrio puertorriqueño del Harlem con uso problemático de crack, un mercado ilegal muy violento y hogares monoparentales femeninos, podemos apreciar importantes semejanzas con el escenario uruguayo que trascienden el lapso temporal y geográfico:

"La incapacidad de los hombres de apoyar a sus hijos y de formar familias estables y afectuosas tiene evidentes bases materiales. En la actualidad, las personas que no han completado los estudios secundarios se hallan excluidas de los empleos legales con los que podrían mantener hogares conyugales según el antiguo estilo patriarcal (...). Esta 'lógica' económica, sin embargo, no es el mero reflejo de una serie de exigencias materiales. Un poderoso legado histórico y cultural opera sobre la desigualdad entre los sexos y estructura los patrones específicos de negligencia y agresión paternos" (Bourgois 2010: 301).

Tal "vulnerabilidad del padre", incapaz de cumplir con los mandatos tradicionales a la vez que reacio a aceptar las nuevas posiciones que parecen establecerse entre los sexos, busca redefinir el sentido de dignidad masculina por "medio de la promiscuidad, la violencia compulsiva y el amplio consumo de drogas" (Bourgois 2010: 230 y 302). Aquí importa, más que los casos concretos (ya que responden a realidades diferentes), la claridad con que el autor identifica aspectos estructurales y políticas estatales, y cómo estos se relacionan con las violencias cotidianas. Las políticas y discursos estatales y sus formas concretas de intervención en el terreno resultan fundamentales para comprender los diferentes procesos que han trazado y dado forma a los espacios urbanos signados por la marginalidad avanzada (Wacquant 1997: 20). Los sentidos sobre las relaciones de género, las diferentes moralidades e incluso la informalidad de los sectores económicos que pueden encontrarse aquí, se construyen a través de las actuaciones y discursos estatales (23).

Para las mujeres, el consumo de PBC adquiere su máxima expresión de ilegitimidad cuando se incumple con el imperativo moral del cuidado. Si bien las prácticas que hacen al cuidado son heterogéneas, históricas y relativas a los sectores sociales, el sentido de lo válido está dado con respecto a las concepciones del cuidado y maternidad dominantes, que claramente no se condicen con las propias, ya sea porque las condiciones materiales no son suficientes, o por el modo en que se relacionan las formas de maternidad y las prácticas de consumo.

Así, el modo en que una mujer usuaria de PBC cuida a sus hijos, puede ser visto como un des-cuido y por lo tanto considerarlo, desde ese lugar, un comportamiento sancionable. Pero las prácticas no solo difieren en relación a la posición social; también aparecen entre las propias usuarias: frente a las situaciones que nos muestran dos usuarias de PBC, podemos observar que si bien no hay conflicto en cuanto a la moralidad en sí misma, compartida por ambas, sí puede haberlo en las prácticas:

"Jimena es una madre soltera con una actitud fuerte y al parecer con ideas bien definidas respecto los 'tipos de consumidoras que hay'. Hablaba desde su lugar como madre, manifestando sus preocupaciones sobre cómo proteger y cuidar a su hija, dado que al encontrarse sola, oficia 'de madre y de padre'. En la conversación que mantuvimos sentenció con seguridad: 'existen los pastosos, los drogadictos y los consumidores. Los pastosos son los que perdieron la noción de todo, no saben donde 
están parados; los drogadictos son los que dejan tirados a los hijos, no les importa nada, se encaman con cualquiera por un chasqui; y los consumidores son aquellos que asumen su dependencia a la droga, pero, a pesar de ello, mantienen sus responsabilidades'. Reconociéndose como 'consumidora' de acuerdo a las categorías de su propio glosario, su mayor responsabilidad, señaló, es el cuidado de su hija por quien 'lucha a muerte'. En correlato con este discurso, durante la charla remarcó varias veces que no podía demorarse ya que debía ir a buscar a la niña a la escuela".

Pastosos, drogadictos y consumidores según señalaba Jimena, no compartirian los mismos códigos, lo cual daría cuenta de que incluso entre los usuarios de PBC no todo es aceptado, sea o no lícito; existen prácticas desacreditables dentro de las propias redes de consumo que pueden ser moralmente sancionadas (24). Es por eso que para Jimena sería muy criticable la actitud de Katherine, como lo es de hecho para ella misma:

"Al momento de conocernos Katherine atravesaba una situación difícil entre una intensa angustia y la fisura (25), en un impasse luego varios días de emparrillamiento (26). Mientras conversábamos contaba cosas sobre su vida, reprochándose a si misma: 'arruiné todo, estoy atrapada en esta mierda' repitió varias veces, tapándose la cara o echándose rendida hacia atrás en la silla. Obtiene el dinero del día a día prostituyéndose en la calle; 'en esta semana creo que fue cuando más sexo tuve con desconocidos' dijo, '¿sabés lo que es ir a pararte ahí para hacer una moneda?, porque si dijeras que es para comida para mis hijos, para un pan, pero no estoy trabajando para mis hijos, no estoy haciendo nada por ellos ¡me prostituyo por un chasqui! ”.

Su relato, en consonancia con el de Jimena, pone de manifiesto que para el caso de determinadas prácticas que serían, aunque lícitas, inapropiadas para otros sectores sociales (como la prostitución), son legítimas para ellas, cuando su finalidad es el cuidado y manutención de los hijos, mientras que se torna una práctica moralmente sancionable cuando lo obtenido se destina al consumo de drogas. Hay que tener en cuenta que la conjunción de vulnerabilidad extrema y consumo compulsivo de PBC no dejan muchas opciones de obtener ingresos para las mujeres, vivan en la calle o no, con lo cual la prostitución es una práctica recurrente $\underline{(27)}$.

Con todo, Katherine también estuvo seis años en la cárcel por cometer el delito de rapiña (robo con violencia física), práctica ilícita que no sería legítima, como sí lo sería el hurto (robo sin violencia), aunque en ciertas circunstancias es tolerada quizás por temor a sufrir represalias. El aceptar o condenar un hurto muchas veces tiene que ver con el lugar donde éste se lleve a cabo: si es en el barrio sería ilegítimo o condenable, mientras que realizado en otros barrios sí sería una práctica tolerada o aceptable. Puede, además, reconocerse que hay conflicto moral en cuanto al robo con violencia o sin violencia: hay sujetos que no admiten el robo con violencia mientras que otros, autoconsiderados como delincuentes, lo exaltan. Míguez (2008) analiza este asunto para el caso argentino: el ladrón, delincuente contra la propiedad que se asume identitariamente en tanto que tal.

En cualquier caso, lo que prima en los varones es la moralidad de la provisión -la obligación moral de proveer- a la que Kessler (2006) llamó “lógica de provisión”. El punto de diferencia, como plantean Fraiman y Rossal (2009), es que no es admisible, al menos para el caso uruguayo, que la "provisión" constituya una lógica enfrentada a otra propia del "trabajo", en lugar de lo cual habría una moralidad de la provisión en continuidad, más o menos conflictiva desde el punto de vista moral, con una vinculada al trabajo. En las mujeres ser "padre y madre" es una necesidad recurrente y ello supone cumplir con la doble obligación moral de cuidar y proveer, haciéndose así admisibles prácticas como la prostitución (28), la cual no es ilícita más allá de la informalidad con que sea ejercida.

En este sentido es de considerar que la prostitución que ejercen muchas de las usuarias es haciendo la calle, o sea por fuera de la reglamentación, los beneficios sociales y los controles médicos. El ejercicio de la prostitución debe ser de las actividades que mayores ingresos dejan a estas mujeres en comparación a otros trabajos, además de dinero inmediato, lo cual es significativo en contextos de privación cotidiana, aspectos que explican en parte que opten por ello. Su informalidad guarda relación con el hecho de que puede constituir una práctica eventual que se alterna con otras formas de adquirir ingresos, como por ejemplo cuidar a un sobrino/a cuando se está más rescatado/a (29), o limpiezas en casa de familiares o vecinos; como también con las dificultades que tienen los usuarios para vincularse con el sistema de salud por la desconfianza que les genera el propio estigma de consumir PBC, aspecto que ha abordado para el 
caso argentino María Epele (2007). Sobre el asunto, Bourgois también señalaba que "una avalancha de mujeres ha inundado el mercado del sexo, lo que ha perjudicado las condiciones laborales de las prostitutas y desatado una epidemia de enfermedades venéreas entre las mujeres jóvenes y los bebés recién nacidos radicados en zonas urbanas. La humillación sexual de las mujeres suele agudizarse cuando las víctimas son adictas al crack, ya que están dispuestas a tolerar mayores niveles de agresión física y verbal con tal de obtener el breve rapto extático que induce la droga" (Bourgois 2010: 293).

Nuevamente observamos que esta población se encuentra sumergida muchas veces en lo más precario del mercado informal; en este caso ejercer la prostitución en la calle (30) y no en establecimientos habilitados, lo cual supone una mayor exposición a diferentes violencias que establecen, por ejemplo, los propios agentes de la "mano derecha" del Estado (Bourdieu 1999).

Es interesante ver cómo la moralidad del cuidado por la cual nuestras interlocutoras se sienten interpeladas, establece un límite entre aquellas prácticas que son admisibles y aquellas que no, en el propio contexto de uso de PBC, lo cual pone en evidencia no solo la heterogeneidad de prácticas de consumo, sino distintos momentos de sus trayectorias en que pueden verse más rescatadas, o con una dependencia más severa que les impide "ser madres" tal como el imperativo moral y el estereotipo social ordenan.

\section{Trayectorias de vida: delito, pasta base y marginalidad avanzada}

La asociación pasta base-delito, recurrente en los discursos del periodismo policial tiene complejidades que conviene tener presente. Generalmente se uniformiza a "los pastabaseros" como sujetos intrínseca o necesariamente inclinados a las actividades delictivas (31), sin tener en cuenta los contextos de producción de esos sujetos, es decir, qué moralidades, subjetividades y trayectorias de vida son propiciadas por las condiciones de violencia estructural en las que se han criado. Los continuos de violencia que llevan a su interiorización y reproducción en formas cotidianas muchas veces no son reconocidas como tales, como lo plantea Bourgois: "La violencia castiga desproporcionadamente a los sectores estructuralmente vulnerables de la sociedad y frecuentemente no es reconocida como violencia ni por las víctimas ni por los verdugos, que a menudo son uno y lo mismo" (Bourgois 2009: 29). Pero que estos sujetos sufran cotidianamente violencias no implica una homogeneizada "infraclase" (Wacquant 2010: 136), de sujetos con trayectorias equivalentes. El conocimiento de sus vidas evidencia una heterogeneidad de experiencias que se contraponen al modo en que se los uniformiza desde los discursos mediáticos:

[Luis, 30 años]

L- De los 7 a los 18 viví en el INAME (32), ¿sacás? A los 12 yo ya empecé a probar las drogas. Empecé con el porro, ya consumía vino, empecé cigarrito, porrito, un día se me tocó para el tema de consumir cocaína y le entré a la cocaína. (...) Eso fue en el promedio entre los doce, y ya para adelante.

G- ¿Consumías en el INAME mismo?

L-Sí.

G- ¿Corrían todas esas cosas?

L- No, pero eso lo hacíamos fuera, afuera de los hogares entendés, porque yo estaba en parte de los hogares abiertos, no estaba en hogares de seguridad, sacás. Estaba por el tema de amparo. [Le decíamos a la funcionaria] "voy a salir a dar una vuelta", y ahí salías, si te gustaba para robar robabas, entendés, para manguear mangueabas. [Después] a los 23 caí preso. Caí preso por rapiña y ta, yo ya estaba consumido, estaba drogado hasta las manijas entendés, ya también consumía en esa época pastillas, que ahí fue cuando empecé a decir, "no esto me está haciendo re mal". Me estaba mandando cualquiera. Y ta, y así fue. Después bueno, así fue mi vida, hasta el día de hoy, fue lo que es, estar en las calles, en la cárcel y ta. Calle, cárcel y lo que fue INAME.

[Manager, 37 años]

M- A los 14 años me fui a Brasil, porque me había fugado de la Colonia (33), y me voy para el interior. Pierdo en Artigas, al hogar rural de varones de Artigas, una viña, trabajaba en una viña allá.

G- ¿A los 14?

M- A los 14 años. Estuve un año en Brasil y me vine. (...) Era delincuente en los tiempos del Chino, del

Pelado, entendés, del Negro, toda esa gente, gurises, delincuentes, ¿no? Cuando conseguía cocaína 
tomaba cocaína (...).

G- Pero vos, ¿te criaste en la Colonia ahí en la Colonia Berro o caíste en algún momento?

M- No, caí en algún momento. Tuve caídas. De menor, mi viejo me sacaba, pero mi vieja no, en ese tiempo era el Consejo del Niño. Si tus dos viejos firmaban, te ibas. Y mi vieja no me firmaba para sacarme.

G- Pero ahí no era por un tema de drogas, digamos...

M- No, no, ahí era porque era delincuente, me dio para robar de chico, entendés, no te voy a mentir. Y ta, salía y robaba.

G- ¿Te criaste en Montevideo?, ¿en qué barrio?

M- En el Borro (...). Había pibitos que andaban robando, catorce quince años. Ya con nueve años fue cuando me saquié un cuarto de los Boy Scouts, que me llevé todas las mochilas para mi casa, pero ta, por el entorno que tenía, entendés, iba a jugar al fútbol con pibes que ya andaban entendés, que me decían "Colonia Berro", pahh para mi era "La Colonia", "tengo que ir a la Colonia", decía yo, ¿entendés?

El consumo problemático de PBC llega como un golpe de gracia a la ya vulnerada situación de algunos de estos sujetos, quienes se encontraban inmersos en estrategias de provisión ilegales y en ambientes con redes de circulación de drogas ilícitas. Esto equivale a decir que el delito ya estaba presente en la cotidianidad de algunos sujetos antes del consumo de PBC. En sus trayectorias de vida han realizado acciones que podrían comportar punición legal pero sin considerar que éstas sean actividades moralmente condenables, poseyendo una suerte de "código penal informal" que no registra ciertas actividades más allá de que sean delictivas para la legislación vigente, como vimos: comprar drogas para compartir con amigos, comprar objetos robados para intercambiar por drogas, intercambiar drogas más allá de su consumo inmediato.

Pero también hay sujetos que provienen de la clase obrera y la militancia política que, en el contexto del uso cotidiano de la PBC, se encuentran con personas de otros orígenes bien diversos.

Las dos personas que vinieron con Lara son mayores de 50 años: Lorenzo, de 51, y Lucía, de 68. Lara (de 39) completa el peculiar trío que conforman. Los tres tienen trayectorias bien distintas, aunque comparten un universo de consumo de PBC.

Lorenzo es usuario de drogas desde niño. En tiempos de dictadura, vivió buena parte del tiempo en la calle, oscilando entre el Consejo del Niño, la calle y alguna persona que lo amparaba. De ese universo de distintas personas de su amparo -"desde que tenía pantalones cortos"- es que está Lucía.

Lucía es instrumentista quirúrgica y consume pasta base desde hace 10 años. Antes solo tenía como vicio ir al Casino de vez en cuando. Desde que probó la PBC jamás pudo dejarla y ello la llevó a tener experiencias de vida absolutamente nuevas y a pasar por espacios sociales que definió como "submundos". Su aspecto y su discurso es típicamente de clases medias y su trayectoria, muy ligada a la de su hijo esquizofrénico, traduce la precariedad de su posición social: "no hay cura ni cuidados para una situación como la de mi hijo", recalcando que sin el apoyo de su familia, quedó desamparada con su hijo y encontró en la PBC una cotidianeidad de experiencias gratificantes, de desinhibición e intensidad. En su pasado tiene una experiencia de haber ido a trabajar a Venezuela y Estados Unidos, siempre con su hijo esquizofrénico a cargo.

Finalmente, Lara es una mujer de 39 años, de padres trabajadores y con un pasado de joven militante comunista. Su trayectoria de consumo de drogas era incompatible con su militancia, pero desde hace 10 años el consumo de pasta base sustituyó a los otros y ahora quiere rehabilitarse ingresando, hoy mismo, en la comunidad Beraca (comunidad religiosa evangélica a la que quiere ingresar porque la admiten junto a su niña).

Estas tres personas de clases sociales diversas tienen en común una cotidianeidad signada por el uso de PBC y por estar sometidos cotidianamente al intercambio de la sustancia, a las alteraciones de su mercado ilícito y a obtener la moneda para participar de él. Lorenzo ha obtenido los recursos durante la mayor parte de su vida mediante robos, Lucía es técnica universitaria del sector salud jubilada y Lara trabajó siempre, incluso buscando suerte en Europa, pero ahora la ayudan irregularmente en su familia, pues no se encuentra en condiciones de trabajar.

Pero esta heterogeneidad de trayectorias que interpela el esbozo simplificante de "perfiles" de adictos y de 
un homogéneo "mundo de las drogas", tal como lo advierte Velho (1994), no niega que más de la mitad de nuestros interlocutores haya tenido la experiencia de la cárcel. Las vivencias del sistema penal son muy distintas para estos sujetos en función de sus redes familiares y los delitos cometidos. Será muy distinta la experiencia de cárcel de un recluso que llega a un espacio social donde hay familiares y amigos, a la experiencia de un preso nuevo y desconocido en el ámbito carcelario.

Las percepciones y sentidos sobre lo legal e ilegal y lo legítimo adquieren otras connotaciones estando -o habiendo estado- en condiciones de reclusión. Si fuera de la cárcel el sujeto puede tomar riesgos (por ejemplo endeudarse) y vivir huyendo, adentro el cuidado debe ser mucho mayor, pues en ella se está sometido a un obligado sedentarismo.

Más allá de la comisión de delitos, las propias circunstancias de consumo de una sustancia ilícita posiciona a los usuarios de PBC en un universo donde la proximidad con lo delictivo es estrecha, siendo en muchas ocasiones víctimas de ello. Estos sujetos viven inevitablemente en un "mundo social" que comparten con policías y agentes del mercado ilegal de las drogas, así como reducidores (personas que compran y venden objetos robados), traficantes y sus perros (cadetes de una boca). Los usuarios de PBC son puestos allí por su propia precariedad y por una legislación que si bien reconoce que consumir drogas no es una actividad delictiva, sí penaliza el "suministro", la "tenencia" y la "negociación" (figuras legales asociadas a los "estupefacientes"), por lo cual quedan a merced de una red de intercambios que los hace participar de ese mundo social.

\section{Consideraciones finales}

En este artículo se ha intentado poner en evidencia tensiones entre los sentidos de lo legal y lo ilegal en relación a las prácticas vinculadas al consumo de pasta base, las moralidades del cuidado y la provisión que interpelan a los sujetos y la normativa vigente en Uruguay. A partir del trabajo de campo fue posible conocer de primera mano distintos aspectos de las formas de subsistencia en la calle, las relaciones familiares y las experiencias en centros de reclusión y con el sistema penal en general de nuestros interlocutores.

En relación a estas dimensiones, es posible afirmar que el uso compulsivo de pasta base, en buena parte de los casos, expulsa a los sujetos de sus hogares (por tiempos prolongados, o por períodos cortos, pero recurrentes en el tiempo), y modifica notoriamente las relaciones familiares. No obstante, ciertos imperativos morales (tradicionales en cuanto a la concepción de relaciones de género que comportan), como son la provisión (masculina) y el cuidado (femenino), siguen estando fuertemente presentes en los discursos, en la construcción de sus memorias y en cómo piensan el futuro, sin perjuicio de que la observación etnográfica revela una multiplicidad de prácticas que se ajustan más o menos a estos imperativos morales.

Así, la legitimidad de las prácticas y las moralidades se relacionan significativamente: si las moralidades interpelan a los sujetos de forma trascendente, sus prácticas se relacionan a una ética local (Zigon 2007), que puede legitimar lo que sería moralmente inaceptable en otro ámbito. En estos términos, los valores se asimilarían a moralidades y los códigos a la ética manifiesta en los comportamientos en ciertos ámbitos. De esta forma, se aprecia una adhesión a los valores tradicionales asociados al hombre proveedor y la mujer cuidadora, pero los códigos, que rigen el comportamiento en los distintos ámbitos son difíciles de sostener en el marco de la fisura y contribuyen al alejamiento de los sujetos a alguna posibilidad de cumplimiento con sus propios imperativos morales.

Viviendo en la calle, los sujetos recurren a prácticas que los posicionan en un espacio donde la proximidad con lo delictivo es estrecha. Calle, barrio y cante son significados de distintas formas porque son espacios que habilitan distinto tipo de relaciones en donde los márgenes de lo tolerado y lo sancionado difieren; es decir donde más allá de lo impuesto por el orden jurídico, los significados son reelaborados permanentemente de acuerdo a la finalidad de las prácticas, de cómo estas posicionan a los usuarios con respecto a otros sujetos (como el traficante, la policía, sus familiares, sus vecinos) y del lugar donde se realicen. Todos estos aspectos inciden sobre cómo se representan, y cómo se ubican estas prácticas en el espacio relacional que constituyen las dimensiones de lo legal, lo legítimo y las moralidades.

Por último, dadas las condiciones mismas de precariedad en que son situados estos sujetos, es muy común 
que tengan experiencias en centros de reclusión, o que sean procesados penalmente, lo cual sin dudas aumenta el grado en que son socialmente excluidos. Los centros de reclusión son lugares donde las relaciones con el marco legal/ilegal adquieren un carácter particular, determinado por las condiciones que impone el encierro. Allí las redes familiares y sociales establecen a su interior relaciones jerárquicas en las que sujetos como nuestros interlocutores, los pastosos, suelen ocupar los lugares más sometidos a violencias.

\section{Notas}

1. Una primera versión de este trabajo fue presentada en la $X$ Reunión de Antropología del Mercosur (Córdoba, julio de 2013) en el GT "Fronteras entre lo legal y lo ilegal: Prácticas, mercados y dinámicas de orden". En especial agradecemos los comentarios de su coordinadora, la Dra. Brígida Renoldi, que permitieron reelaborar diferentes aspectos del mismo. Se agradecen, asimismo, las pertinentes indicaciones realizadas en el proceso de publicación del artículo.

2. Se agradece muy especialmente a todos los participantes del estudio. Sus nombres y referencias a lugares que podrían comprometerlos han sido modificados para proteger su identidad. El término "población oculta" refiere a que se trata de sujetos que no llegan a ser captados por las encuestas sobre uso de drogas en el país, encuesta entre alumnos de la enseñanza secundaria y encuesta continua de hogares.

3. Achique o achiques pueden tener distintos significados. Achique(s) se considera a algún lugar provisorio para quedarse o pernoctar, para achicar. Asimismo achicar refiere a bajar, disminuir el consumo. Se achica un consumo cuando se reducen las cantidades; se busca salir de la calle, del ruido, achicando en algún lado.

4. Consumir en una medida que los criterios epidemiólogos designan como problemático. Si bien cada sujeto tiene su propia medida, para el caso uruguayo el consumo sería problemático en la mayoría de los usuarios, pues éstos son, en general, usuarios cotidianos en un porcentaje que pasa el 50\%: "El 53\% de los consumidores del último año de pasta base muestra signos de dependencia, según el Criterio de Clasificación Internacional de Enfermedades décima versión, recomendado por OPS." (Observatorio Uruguayo de Drogas 2012: 33)

5. Procurar o salir a pegar, es salir a la obtención de sustancias ilícitas. Ambas palabras provienen del portugués, como buena parte de la jerga utilizada en contextos de consumo de sustancias ilícitas en Montevideo y el Interior del país.

6. Abreviación de cantegril, forma irónica ya antigua (Cantegril Country Club de Punta del Este), de llamar en Uruguay a los asentamientos irregulares.

7. Wacquant hace una diferencia semántica entre "lugar" y "espacio". No es lo mismo un lugar (comunidad de sentirse "entre sí" y en relativa seguridad) que un espacio (en el cual hay que cuidarse del otro, donde se sufre descalificación lateral y distanciamiento mutuo) (Wacquant 2007). No obstante esta distinción es relacional, de acuerdo a quién la enuncie.

8. De acuerdo a lo planteado por Saraví (2004: 35-36) "el barrio como espacio de relación e interacción social se asocia a la noción de espacio público local. Entendido de esta manera, constituye el espacio público más inmediato; el primer encuentro público al abrirse la puerta de lo privado. (...) Es decir, no se trata de un espacio público cualquiera, sino de un espacio de tránsito que separa (o une) el mundo de lo público y lo privado".

9. Los cantegriles son producto del asentamiento de migrantes del campo a la ciudad de Montevideo desde finales de los años 40, en algún sentido son producto de la proletarización implicada en la política de sustitución de importaciones del Estado uruguayo en ese momento. En cambio, el crecimiento enorme de los asentamientos irregulares en los años 90 bien podría decirse que es resultado de lo que Wacquant (2007) ha llamado "marginalidad avanzada", producto del giro neoliberal del capitalismo y la retirada del Estado. 
10. En todos los entrevistados pudimos apreciar una adhesión moral muy fuerte a una concepción de hombre proveedor y mujer cuidadora y, correlacionado con lo anterior, una idea de familia tradicional que constituye un ideal preciado, que, en algunos de nuestros interlocutores, aunque jamás la tuvieron en sus trayectorias, lo consideran como lo "normal". El tener una vida normal es tener una familia normal y cumplir con esas obligaciones morales: proveer y cuidar.

11. La interpelación moral hacia el usuario de PBC ocurre, según lo narrado por los varones, en cuanto el incumplimiento de las obligaciones en relación a la familia determina que irse a la calle pasa a ser una opción moralmente virtuosa: ya que no se puede cumplir con el imperativo de proveer, no es admisible constituirse en una carga.

12. En un recorrido que realizó el equipo de investigación varios meses luego de finalizado el trabajo de campo, por la zona donde se contactó a buena parte de los entrevistados, nos reencontramos con uno de ellos que se dedica a cuidar coches y él comentaba que "por ahí ya no andaban muchos pibes", dado que muchas "bocas" habían sido "limpiadas" por la policía, obligándolos a desplazarse hacia otros barrios.

13. Básicamente, intercambio de sustancias prohibidas por objetos provenientes de diferente origen. Los delitos en cuestión son receptación (artículo 350bis del Código Penal) y negociación o suministro de estupefacientes (artículo 31 de Ley 17.016).

14. Neri suele ser el término usado para este tipo de relaciones de compañerismo. Ñeri es tomado de la jerga carcelaria.

15. Al contrario de lo que se podría suponer (si uno va en grupo estaría más protegido), muchos usuarios de PBC afirman que es más seguro andar solo. No obstante una práctica que nos fue referida realizando trabajo de campo, al parecer bastante reciente, hace que "caminar solo" también se convierta en una práctica riesgosa. Varios de nuestros entrevistados manifestaron que en la calle los consumidores de PBC son atacados al estar solos por grupos de jóvenes a quienes llaman los antipasta; estos grupos agreden brutalmente a quienes ellos identifican como pastosos sin recibir ningún tipo de sanción, estando incluso la policía en conocimiento de ello. Al respecto uno de nuestros interlocutores señaló que presenció uno de estos procedimientos, donde los vecinos llamaron a la policía porque el sujeto agredido saltó las rejas de una casa para estar a salvo y no para que detuvieran a los agresores.

16. Es imposible no hacer mención a las reflexiones de Da Matta (1985) sobre la relación de lo público y lo privado implicado en la casa y la calle.

\section{El Manager fue uno de nuestros interlocutores más cercanos.}

18. La gráfica expresión reafirma lo dicho más arriba sobre la preferencia por caminar solo, lo cual implica también encontrar un lugar donde descansar tranquilo.

19. La farmacia aludía a la boca de venta de PBC, la ferretería al depósito que compra los materiales recolectados. Es importante hacer notar aquí cómo el Manager utiliza las palabras con sarcasmo, para resaltar la informalidad y precariedad de sus actividades. A veces, ante el discurso del otro, pareciera que se buscara "esencializar" cada palabra, como si respondiera exclusivamente a una jerga o dialecto propio del grupo en cuestión. Efectivamente, se pueden encontrar palabras específicas o usos que difieren de acuerdo a la posición en el espacio social; pero también hay en cada sujeto innovación, sarcasmo y una amplia gama de recursos en el uso del idioma para expresarse. Insistir en demasía en esa "esencialización" implica, en alguna medida, negar parte de la capacidad de agencia o pensamiento de ese otro. Por supuesto que el uso individual puede tornarse grupal -la sarcástica metáfora sobre la 'farmacia' del Manager termina siendo sinónimo de boca, por caso-, pero este proceso es común a la lengua toda, a través por ejemplo, de las "metáforas muertas", como bien mostrara Ricoeur (1998: 65).

20. Gira, estar de gira: implica pasar varios días consumiendo en mayor medida que lo habitual, descansando y alimentándose muy escasamente. Los usuarios de PBC pueden consumir diariamente algunos chasquis (dosis mínima de PBC), así como eventualmente estar de gira, cuando obtienen recursos que les permitan obtener una mayor cantidad.

21. Central de generación eléctrica frente a la Bahía de Montevideo. 
22. Cabe señalar que en las situaciones donde se mencionó que existía una mujer "esperando" a que volviera el varón al hogar, siempre había una familia conformada, es decir, tenían hijos.

23. Cada Estado produce sus marginalidades. En Uruguay cabe destacar la construcción del Estado-nación a través de un discurso igualitarista y de instituciones "normales" -de las cuales la escuela es el modelo (Guigou 2003)- para lograr ese objetivo. Distinto es el caso norteamericano y su "multiculturalismo", donde el Estado contribuyó a la configuración de espacios de segregación racial y étnica en los ghettos (Wacquant 1997).

24. Un ejemplo de sanción lo encontramos en la experiencia de una muchacha a quienes otros usuarios del mismo barrio le dijeron que no podía "quemar en cualquier lado". Fue común entre nuestros interlocutores escuchar que no fumaban ante niños, así como también buscaban lugares alejados o poco visibles para ocultarse de otros actores que podían sancionarlos como los vecinos o la policía.

25. Fisura es lo que siente un sujeto/a cuando desea consumir. Más que al deseo refiere a la necesidad física producto de la dependencia química a una sustancia.

26. Emparrillarse, emparrillamiento refiere también a los momentos en que se consume de corrido durante un cierto período. Como vemos tiene un sentido similar al de estar de gira, aunque ésta última categoría implicaría un período mayor de tiempo de consumo, mientras que el emparrillamiento puede durar una noche por ejemplo.

27. Lo cual coincide con experiencias de otros contextos sociales. Véase Harding y Hamilton (2009).

28. En Uruguay la prostitución es legal desde comienzos del siglo $X X$ y su legalización implicó una regulación de la actividad fundamentada en los aspectos sanitarios (Trochón 2003). El mismo tipo de argumentos en base a los cuales se legisló la regulación responsable de la marihuana. El proceso de secularización tuvo su correlato en la medicalización del país (Barrán 1992) y el desarrollo de una verdadera "religión civil" (Guigou 2003) que sacraliza la política privatizando los discursos de orden religioso.

29. Mejor llevado, consumiendo menos.

30. Si bien las cifras estadísticas muestran que la prevalencia de ITS son bajas en términos generales, éstas aumentan considerablemente entre ciertos sectores de la población, entre ellos en la que nos enfocamos en este artículo. Para el caso del VHI, un estudio paralelo al nuestro (OUD, MSP 2013) muestra una prevalencia de más de $6 \%$ (más del $5 \%$ constituye una población vulnerable según Naciones Unidas), varias veces más alta que la prevalencia de la población general según datos del Ministerio de Salud Pública (MSP 2010).

31. Sea por causas "farmacológicas", por necesitar dinero para el consumo o por razones "sistémicas" (Goldstein 1985), los consumidores de PBC son siempre sospechosos (Albano et al. 2013). Sin embargo, nos encontramos con trayectorias signadas por una violencia estructural que las hace vulnerables a participar del mercado ilegal en varias de sus facetas $y$, muchas veces, antes de iniciarse al consumo problemático de PBC. En cuanto a la concreción de delitos, los consumidores problemáticos de PBC son menos eficientes para el delito contra la propiedad aunque blancos más fáciles del sistema penal; algunos de ellos sí realizarán "delitos de bagatela", como robar plantas de los jardines de las casas, timbres, metales, mangueras de aire acondicionado y, con mayor riesgo, cables de suministro eléctrico y alumbrado público.

32. Instituto Nacional del Menor (anteriormente Consejo del Niño). Actualmente INAU (Instituto del Niño y Adolescente del Uruguay).

33. Se refiere a la Colonia Berro, la cual comprende un conjunto de hogares y centros de detención para adolescentes infractores. 
Albano, Giancarlo (y otros)

2013 "Pasta base de cocaína, cárcel y continuos de violencia", Espacio abierto. Montevideo, Revista del CIEJ-AFJU, n 18: 53-61.

2014 "Caminando solos", en Héctor Suárez y Marcelo Rossal (eds.), Fisuras. Dos estudios sobre pasta base de cocaína en el Uruguay. Montevideo, FHCE-OUD.

Bardazano, Gianella

2012 "Se presume culpable. Sobre la justificación de las decisiones judiciales relativas a la interpretación del artículo 31 del decreto ley 14.294 en su redacción dada por la ley 17.016", Aporte universitario al debate nacional sobre drogas. Montevideo, CSIC: 39-61.

Barrán, José Pedro

1992 "Medicina y sociedad en el Uruguay del Novecientos. Tomo 1: El poder de curar. Montevideo, Ediciones de la Banda Oriental.

Bourdieu, Pierre

1999 Contrafuegos. Montevideo, Anagrama Editorial.

Bourgois, Philippe

2009 "Treinta años de retrospectiva etnográfica sobre las violencias en las Américas", en J. López García, S. Bastos y M. Camus (comp.), Guatemala: Violencias desbordadas. España, Servicio de Publicaciones de Universidad de Córdoba: 29-62.

2010 En busca de respeto. Vendiendo crack en Harlem. Buenos Aires, Siglo XXI Editores.

Da Matta, Roberto

1985 A casa e a rua: espaço, cidadania, mulher e morte no Brasil. Brasiliense, Río de Janeiro.

Epele, María

2007 "La lógica de la sospecha. Sobre criminalización del uso de drogas, complots y barreras de acceso al sistema de salud", Cuadernos de Antropología Social, n² 25: 153-170.

Feldman, Harvey (y Aldrich, Michael)

1990 "The Role of Ethnography in Substance Abuse Research and Public Policy: Historical Precedent and Future Prospects", en Elizabeth Lambert y Wayne Wiebel (orgs.), The Collection and Interpretation of Data from Hidden Populations. Washington, NIDA.

Fraiman, Ricardo (y Marcelo Rossal)

2009 Si tocás pito te dan cumbia. Esbozo antropológico de la violencia en Montevideo. Montevideo, AECID/PNUD/MI.

2011a De calles, trancas y botones. Una etnografía sobre pobreza, violencia y solidaridad urbana. Montevideo, BID/MI.

2011b "Políticas de ciudadanía y relaciones de vecinazgo en un barrio de Montevideo", Papeles del CEIC, vol. 1 (69).

Garibotto, Giorgina

2010 "Cárceles y drogas en Uruguay", Sistemas sobrecargados. Leyes de drogas y cárceles en América Latina. Buenos Aires, TNI WOLA: 82-89.

Goldstein, Paul

1985 "The drugs/violence nexus: a tripartite conceptual framework", Journal of Drug Issues, vol. 15: $493-506$.

Guigou, Nicolás

2003 La nación laica: religión civil y mitopraxis en el Uruguay. Montevideo, Ed. La Gotera.

Harding, Rachel (y Paul Hamilton)

2009 "Working girls: Abuse or choice in street-level sex work? A study of homeless women in Nottingham", British Journal of Social Work, vol. 6: 73-97.

Kessler, Gabriel 
2006 Sociología del delito amateur. Buenos Aires, Paidós.

Míguez, Daniel

2008 Delito y cultura. Los códigos de la ilegalidad en la juventud marginal urbana. Buenos Aires, Biblos.

Observatorio Uruguayo de Drogas

2012 V Encuesta nacional de hogares sobre consumo de drogas. Montevideo, JND/Presidencia de la República.

Observatorio Uruguayo de Drogas / Ministerio de Salud Pública

2013 Seroprevalencia de VIH/SIDA y de conocimientos, actitudes y prácticas entre usuarios de cocaína, pasta base, crack y otros derivados de la hoja de coca en Montevideo y su área metropolitana. Informe final inédito.

Ricoeur, Paul

1998 Teoría de la interpretación. Discurso y excedente de sentido. México, Siglo XXIEditores.

Saraví, Gonzalo

2004 "Segregación urbana y espacio público: los jóvenes en enclaves de pobreza estructural", Revista de la CEPAL, $\mathrm{n}^{\circ}$ 83: 33-48.

Silva de Sousa, Rosinaldo (e Isabel Anaya Ferreira)

2004 "Narcotráfico y economía ilícita: las redes del crimen organizado en Río de Janeiro", Revista Mexicana de Sociología, nº6/1: 141-192.

Trochón, Yvete

2003 Las mercenarias del amor. Prostitución y modernidad en el Uruguay (1880- 1932). Montevideo, Taurus.

Velho, Gilberto

1994 "A dimensao cultural e política dos mundos das drogas", en A. Zaluar (comp.), Drogas e cidadania: repressao o reduçao de danos? Sao Paulo, Ed. Brasiliense: 23-29.

Veneziano, Alicia

2008 "La participación ciudadana en la descentralización de Montevideo: aprendizajes y reflexiones desde los Noventa", Revista Uruguaya de Ciencia Política, nº 17/1: 203-227.

Wacquant, Loïc

1997 "Elias en el ghetto", Apuntes de investigación del CECYP, n ¹: 13-21.

2007 Los condenados de la ciudad. Buenos Aires, Siglo XXIEditores.

2010 Parias urbanos. Marginalidad en la ciudad a comienzos del milenio. Buenos Aires, Manantial.

Zigon, Jarrett

2007 "Moral breakdown and the ethical demand. A theoretical framework for an anthropology of moralities", Anthropological Theory, v. 7 (2). 